unable to give consent? Patients have not only the right to refuse treatment, but should also have the right to consent. Brabins, C., Butler, J. \& Bentall, R. (1996) Consent to
neuroleptic medication for schizophrenia: clinical, ethical and
legal issues. British Journal of Psychiatry, 168, 540-544.
SCHNEmER, L., Pollock, V. E. \& LrNESs, S. A. (1990) A
meta-analysis of controlled trials of neuroleptic treatment in
dementia. Journal of the American Geriatrics Society, 38,
553-563.

\section{Hairmyres Hospital}

East Kilbride G75 8RG

Knightswood Hospital

Glasgow G13 $2 X F$

\section{Obstetric complications and schizophrenia}

SIR: We read with interest the article by Kendell et al (1996) on the association between obstetric complications and development of schizophrenia later in life. Pre-eclampsia was the obstetric complication with the highest correlation with the development of schizophrenia. We would draw to the authors' attention the interesting observation that pre-eclampsia may, like schizophrenia, be represented in excess during the winter-early spring months (Boyd et al, 1986; Obed et al, 1994). The authors claim that, despite the evidence for a contribution of foetal anoxia in the aetiology of schizophrenia, improved obstetric care in the industrialised countries has not resulted in a fall of the incidence of schizophrenia. Improved obstetric care has indeed provoked a drastic fall in neonatal mortality, but not necessarily a lower incidence of babies surviving with anoxic damage. It is therefore possible that, despite improved obstetric care, the proportion of babies who survive after anoxic damage, and are therefore probably more liable to develop schizophrenia, has not changed significantly. An indirect confirmation to this hypothesis is that, apart from pre-eclampsia, the only other obstetric factor which in Kendell's study predicted a future development of schizophrenia was a longer stay in hospital for the infant.

Boyd, J. H., Pul ver, A. E. \& Stewart, W. (1986) Season of birth: schizophrenia and bipolar disorder. Schizophrenia Bulletin, 12, 173-186.

Kendel, R. E., Juszczak, E. \& Cole, S. K. (1996) Obstetric complications and schizophrenia: a case control study based on standardised obstetric records. British Journal of Psychiatry 168, 556-561.
Obed, S. A., Wilson, J. B. \& Elkins, T. E. (1994) Eclampsia: 134 consecutive cases. International Journal of Gynaecology and Obstetrics, 45, 97-103.

I. FALKOWSKI
M. ProcoPIO
$\begin{aligned} & \text { Royal London Hospital (St. Clement's) } \\ & \text { London E3 } 4 L L\end{aligned}$

Institute of Psychiatry

P. TOSETTO

\title{
Excess mortality of mental illness
}

SIR: We suggest that the methodology used in Baxter's study (1996) has produced an underestimate of the true excess mortality in a psychiatric population. Excess mortality in mental illness is greatest in young people, early in the course of their illness. A mixed cohort therefore includes many people who have already survived the period of greatest excess mortality. The Danish study of mortality in first episode schizophrenia (Mortensen \& Juel, 1993) found an aggregate excess mortality of 3.34 , twice the rate of 1.59 found in the Salford study. This may also be an underestimate of the true mortality, as some people die (e.g. from suicide), without being recognised by the mental health services. The second source of error is inherent in the record linkage methodology, which misses deaths that are not recorded on the registers. The size of the error depends on factors such as the accuracy of the registers and the record linkage process, and the frequency of emigration and change of name among the study cohort. We are currently conducting a follow-up study of 360 people with schizophrenia, in which case register information has been verified by other means. We found that 4 of 66 deaths $(6 \%)$ were not picked up by the initial record linkage. Two were recorded as alive on FHSA databases, and two died abroad.

These comments do not invalidate Baxter's conclusions, but confounding variables such as the demographic characteristics of the cohorts and the length of follow-up will have to be standardised before the results of different studies can be compared.

BAXTER, D. N. (1996) The mortality experience of individuals on the Salford psychiatric case register. I. All-cause mortality. British Journal of Psychiatry, 168, 772-779.

Mortensen, P. B. \& JuEl, K. (1993) Mortality and causes of death in first admitted schizophrenic patients. British Journal of
Psychiatry, 163, 183-189. 